\title{
Mechanism of zinc damaging to blast furnace tuyere refractory
}

Xuefeng $Y A N G^{1,2) *}$, Mansheng $C H U^{3)}$, Fengman $S H E N^{3)}$ and Zhuming $Z H A N G^{2)}$

1) School of Minerals Processing and Bio-engineering, Central South University, Changsha 410083, China

2) Technology Center, Kunming Iron and Steel Limited Company, Kunming 650302, China

3) School of Materials and Metallurgy, Northeastern University, Shenyang 110004, China

Manuscript received 23 February 2009; in revised form 14 April 2009

\begin{abstract}
The phenomena of tuyere upward-warp have been found at No.6 blast furnace in Kunming Steel Company China after its blow-in, which has made a great impact on the practical production of the furnace. Thus, a number of efforts have been made to elucidate the mechanism of this phenomenon. The results of investigation and tests revealed that the enrichment and expansion of zinc in the tuyere bricks is the main factor leading to the tuyere upward-warp. The eroding behavior of zinc is that the inner structure of the tuyere bricks turns from dense to loose with entering, enriching and expanding of zinc, which forms spot-like $\rightarrow$ stripe-like $\rightarrow$ ditch-like $\rightarrow$ vein-like $\rightarrow$ tumorlike eroding passage. Additionally, it is found that the sequence of deleterious elements entering the tuyere refractory is $\mathrm{K}, \mathrm{Na}, \mathrm{Zn}$ and $\mathrm{Pb}$, respectively. Finally, the phenomena and process of zinc crystallization and growth in the refractory have been clearly observed and recorded during this investigation.
\end{abstract}

KEY WORDS Blast furnace; Tuyere; Refractory; Zinc; Erosion; Deleterious elements

\section{Introduction}

No.6 blast furnace in Kunming Steel China, with an inner volume of $2000 \mathrm{~m}^{3}$, blew in in 1998. Totally, 26 tuyeres are set. And the furnace uses the ceramic cup structure of compound brown corundum brick and self-baking carbon block with half graphitization and low porosity. The total depth of the bottom is $3.05 \mathrm{~m}$, in which the lowest first layer is big baking $\mathrm{C}-\mathrm{SiC}$ block with half graphitization, the middle second-fifth layers are selfbaking carbon block with half graphitization and low porosity and the top two layers are compound brown corundum brick. The side part of the hearth used self-baking carbon block from the seventh to fifteenth layer, big baking C-SiC block with half graphitization from sixteenth to twenty-first layers, and small baking C-SiC block with half graphitization in the region near the furnace shell. In addition, 8-layer compound brown corundum bricks

\footnotetext{
${ }^{*}$ Corresponding author. Senior engineer, PhD; Tel.: +86 8718603257 or +86 13769138246 ;

Fax: +868718603955 .

E-mail: kgyxf@163.com (Xuefeng YANG)
}

DOI: $10.1016 / S 1006-7191(08) 60123-4$ 
and 12-layer tuyere assembled bricks are laid above the brickwork of the hearth.

Unexpectedly, some unusual phenomena have occurred since 2002. Table 1 listed the statistical data of the tuyere upward-warp in 2002. According to Table 1, remarkable upward-warp took place in each tuyere of No.6 blast furnace, with the range from $2.4^{\circ}$ to $8.3^{\circ}$, and averaged value $5.79^{\circ}[1]$. Evidently, the upward-warp of tuyeres had a serious impact on the blasting and routine operation of the furnace ${ }^{[2]}$.

In order to investigate the reason of tuyere upward-warp, the authors have laid the emphasis on the effects of the deleterious elements, mainly zinc, on the tuyere refractory, and make a number of experimental researches to elucidate the behaviors of zinc in the assembled bricks of the tuyeres through obtaining the sample of tuyere assembled bricks and analyzing the variation of the contents of $\mathrm{K}, \mathrm{Na}, \mathrm{Zn}$ and $\mathrm{Pb}$.

Table 1 Measurement results of the tuyere upward-warp in No.6 blast furnace

\begin{tabular}{|c|c|c|c|c|c|c|c|c|c|c|c|c|c|}
\hline No. of the $t$ & No.1 & No.2 & No.3 & No.4 & No.5 & No.6 & No.7 & No.8 & No.9 & No.10 & No.11 & No.12 & No.13 \\
\hline $\begin{array}{l}\text { Upward-warp } \\
\text { angle/deg }\end{array}$ & 6.3 & 4.5 & 3.6 & 7.1 & 6.0 & 6.1 & 8.3 & 4.9 & 5.7 & 2.4 & 5.8 & 6.8 & 4.3 \\
\hline No. of the tuyere & No.14 & No.15 & No.16 & No.17 & No.18 & No.19 & No.20 & No.21 & No.22 & No.23 & No.24 & No. 25 & No.26 \\
\hline $\begin{array}{c}\text { Upward-warp } \\
\text { angle/deg }\end{array}$ & 6.7 & 5.2 & 7.5 & 7.1 & 7.9 & 6.9 & 3.3 & 4.5 & 5.2 & 5.5 & 7.2 & 5.7 & 5.7 \\
\hline
\end{tabular}

\section{Analysis of Zinc Damage and Zinc-enriched Region}

With respect to the damage of deleterious elements on the brick lining of blast furnace, many blast furnace operators generally emphasized on $\mathrm{K}, \mathrm{Na}$ and $\mathrm{Pb}$ but little on $\mathrm{Zn}$, and even sometimes thought that zinc had no erosion on the furnace refractory. Some researchers, however, have found that zinc and its oxides bring great harm to the brick lining of blast furnace ${ }^{[3-5]}$ since the volume will expand by $54 \%, 68 \%$ and $83 \%$ respectively in the reaction from $\mathrm{Zn}$ to $\mathrm{ZnO}$, from $\mathrm{ZnO}$ to $\mathrm{ZnS}$ and from $\mathrm{Zn}$ to $\mathrm{ZnS}$. Serious zinc accidents had once occurred on the blast furnace of one ironmaking plant in China ${ }^{[6]}$. At that time, the zinc load of the charged burdens attained to $0.54 \mathrm{~kg} / \mathrm{THM}$. The primary resource of the deleterious element of $\mathrm{Zn}$ in the blast furnace is from the charged burdens. During the operation, the $\mathrm{Zn}$ is circulated and enriched in the mixture of hot metal and molten slag in the hearth, and erodes the lining bricks, which finally resulted in the sticking of the furnace wall and the burnout of the tuyeres and consequently worsened the efficiency index and smooth running of the blast furnace. As a result, this plant put forth that the zinc load of the burdens should be controlled below $0.15 \mathrm{~kg} / \mathrm{THM}^{[6]}$.

Table 2 gives the zinc balance of No.6 blast furnace in Kunming Steel China ${ }^{[1]}$. For this blast furnace, the zinc load $(0.81 \mathrm{~kg} / \mathrm{THM})$ is relatively high among the deleterious elements in the burdens while the zinc-removal ratio is low (only 88.52\%). Thus, more emphasis should be laid on elucidating the effects of zinc on furnace refractory.

The melting point of zinc is $419{ }^{\circ} \mathrm{C}$ while the boiling point $907^{\circ} \mathrm{C}$. The zinc enters the furnace as $\mathrm{ZnS}$ with the charged iron-bearing burdens, then it transforms into $\mathrm{ZnO}$ in the furnaceand it is reduced in the zone with the temperature above $1000{ }^{\circ} \mathrm{C}$, generating gaseous zinc ${ }^{[7-9]}$ through the following reaction.

$$
\mathrm{ZnO}+\mathrm{C}=\mathrm{CO}_{(\mathrm{g})}+\mathrm{Zn}_{(\mathrm{g})}
$$


Table 2 Zinc balance of No.6 blast furnace in Kunming Steel China

\begin{tabular}{cccccccc}
\hline \multirow{2}{*}{ Time } & \multicolumn{2}{c}{ In } & & \multicolumn{2}{c}{ Out } & Hold-up \\
\cline { 2 - 3 } & $\begin{array}{c}\text { Zinc load } \\
\mathrm{kg} / \text { THM }\end{array}$ & $\begin{array}{c}\text { Total input } \\
\mathrm{t}\end{array}$ & & $\begin{array}{c}\text { Zinc removal } \\
\mathrm{kg} / \text { THM }\end{array}$ & $\begin{array}{c}\text { Total removal } \\
\mathrm{t}\end{array}$ & $\begin{array}{c}\text { Remal ratio } \\
\%\end{array}$ \\
\hline 2001 & 0.786 & 1170.48 & & 0.642 & 953.47 & 217.01 & 81.46 \\
2002 & 0.835 & 1286.28 & & 0.706 & 1087.57 & 198.71 & 84.55 \\
2003 & 0.885 & 1224.98 & & 0.794 & 1099.02 & 125.96 & 89.72 \\
2004 & 0.764 & 1055.57 & & 0.801 & 1106.69 & -51.12 & 104.84 \\
2005 & 0.551 & 871.57 & & 0.558 & 883.93 & -12.37 & 101.16 \\
2006 & 0.480 & 810.23 & & 0.477 & 809.68 & 0.55 & 99.93 \\
2007 & 0.481 & 893.06 & & 0.447 & 806.07 & 86.99 & 90.25 \\
2008 & 0.547 & 726.21 & & 0.526 & 697.33 & 28.88 & 96.02 \\
Average & 0.666 & 1004.80 & & 0.619 & 930.47 & 74.33 & 93.49 \\
\hline
\end{tabular}

The reaction (1) is endothermic and all the products are gaseous matters. So, high system pressure and low temperature is not preferable to the occurrence of the above reaction. Noted that, compared with the other mid-or small scale blast furnace, the in-furnace pressure is comparatively higher and the corresponding position of the high temperature zone is relatively lower for the No.6 blast furnace of Kunming Steel. That is to say, the damage of zinc on the furnace is mainly concentrated in the regions of tuyeres with regard to No.6 blast furnace.

\section{Exprimental Research on the Behaviors of Zinc in the Tuyeres Bricks}

\subsection{Sequence of the deleterious elements entering tuyeres bricks}

The researchers have contrastively tested and analyzed the tuyere refractory samples that are eroded in the different degrees. The detailed experiment results are shown as follows.

Fig.1 shows the photos and results of SEM and EPMA test for the tuyere refractory samples after the erosion in the different degrees.

In Fig.1, there are four tuyere refractory samples named as (a), (b), (c) and (d). From Sample (a) to (d), the eroded degree tends to worsen. Fig.1a-1d are the photos of each refractory surface after SEM test while Fig. $1 \mathrm{a}^{\prime}-1 \mathrm{~d}^{\prime}$ are the corresponding results of EPMA test for inner components of each tuyere refractory sample.

The appearance of Sample (a) is almost intact (in Fig.1a). Gray-white spots-like erosion exists on the surface of Sample (b) (in Fig.1b). The gray-white stripe-like and ditch-like erosion is generated on the surface of Sample (c) (in Fig.1c). Finally, the surface of Sample (d) has received serious erosion and lost the original appearance (in Fig.1d). The bottom left part of Fig 1d is the corundum aggregate while the top right part is the matrix. In the surface of Sample (d), the strip- and ditch-like eroding passage have further spread to be vein-like erosion zone, which separated the corundum aggregate from the matrix.

Further, more details are obtained through the EMPA test. The analysis by EPMA clearly shows that: Regarding Sample (a), small amount of $\mathrm{K}$ has entered the inner of Sample (a) (in Fig.1a') although the surface looks almost unchanged as mentioned above. Additionally, the elements of $\mathrm{Na}, \mathrm{Zn}$ and $\mathrm{Pb}$ are not found. For Sample (b), Fig.1b' shows that the content of $\mathrm{K}$ evidently increases and small amount of $\mathrm{Na}$ is observed in the region with gray-white spots. At this time, no $\mathrm{Zn}$ and $\mathrm{Pb}$ enter the inner of the refractory. For 

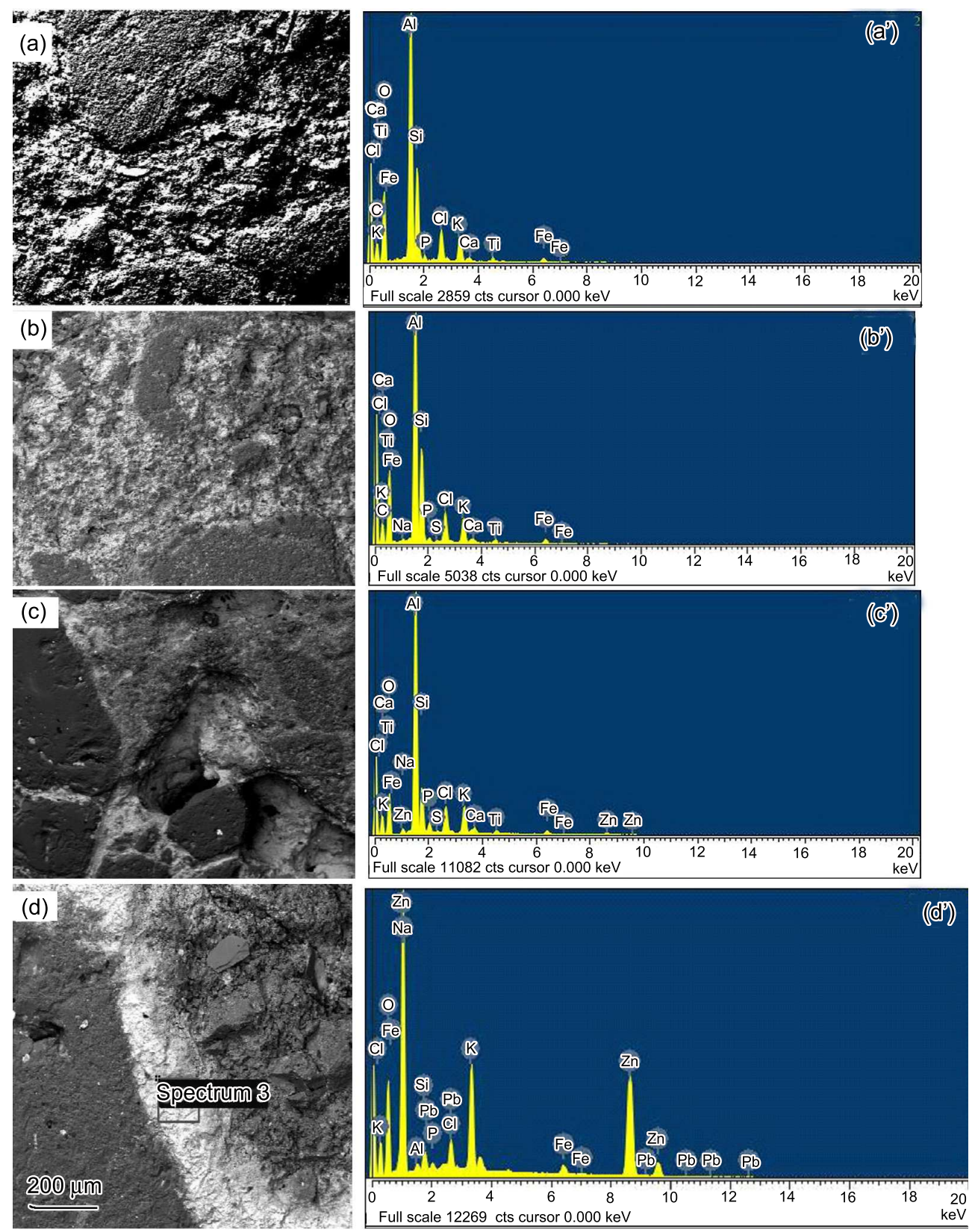

Fig.1 Photos of SEM $(\mathrm{a}-\mathrm{d})$ and EPMA $\left(\mathrm{a}^{\prime}-\mathrm{d}^{\prime}\right)$ test for the tuyere brick samples with different erosion degrees.

Sample (c), the EMPA test clarified that the elements of $\mathrm{K}, \mathrm{Na}$ and $\mathrm{Zn}$ existed in the regions with gray-white strip- and ditch-like erosion but no $\mathrm{Pb}$ was observed (in Fig.1c'). With respect to Sample (d) it received the worst erosion, the silver-white part in the center of vein-like erosion zone contains mainly $\mathrm{Zn}$ and its oxides besides the oxides of $\mathrm{K}$ and $\mathrm{Na}$ (in Fig.1d'). Furthermore, small amount of $\mathrm{Pb}$ is observed in this case.

Based on the above observation, test and analysis, it is concluded that: (1) The sequence of the deleterious elements entering the tuyere brown corundum bricks is $\mathrm{K} \rightarrow \mathrm{Na} \rightarrow \mathrm{Zn} \rightarrow \mathrm{Pb}$; 
(2) The element $\mathrm{K}$ having strong eroding ability first enters the inner of tuyere brick along the interface of corundum aggregate and the matrix and/or on the other weak locations of the bricks, and forms the erosion passage. Then, Na and Zn successively enter following K; (3) With the invasion and enrichment of the above deleterious elements, the inner structure of the tuyere bricks turns from dense to loose, and spot- $\rightarrow$ stripe- $\rightarrow$ ditch- $\rightarrow$ vein-like eroding passages are generated successively.

In order to ascertain the damage of zinc to the refractory, the microscopic observation by SEM and component analysis by EMPA have been done. Fig.2 gave the results of SEM and EPMA tests for the zinc-enriching region corresponding to another tuyere brick sample withstanding more serious erosion than all the others discussed in Fig.1.
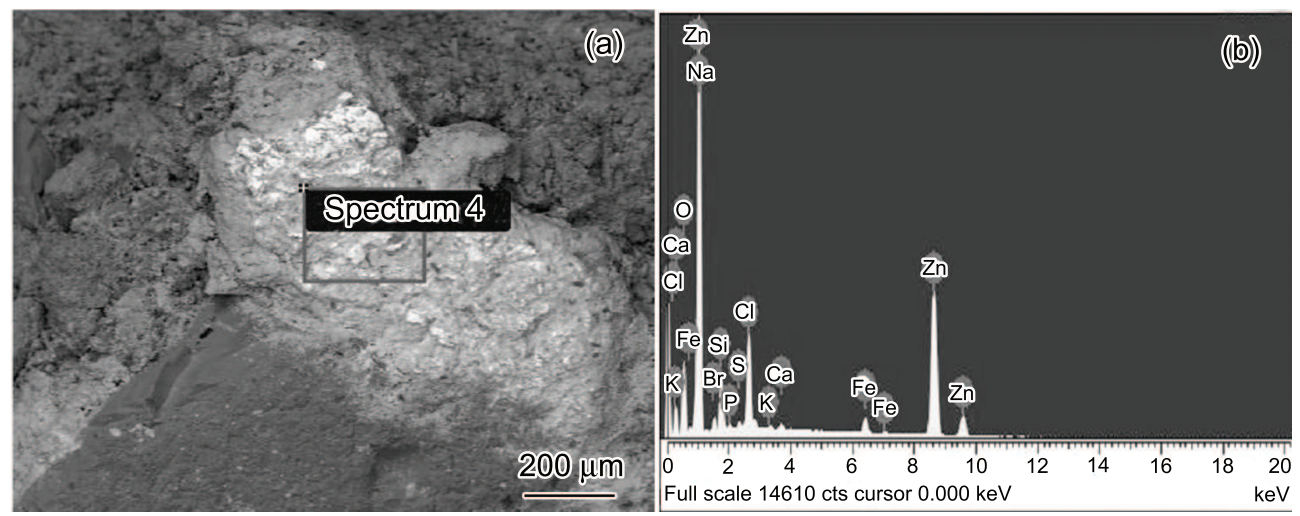

Fig.2 Results of SEM and EPMA tests for zinc-enriching region in tuyere bricks.

For the sample shown in Fig.2, the inner structure of the brick tends to be much looser and begins to swell. The vein-like eroding block further expands, and gradually turns to be tumor-like one. To this step, the brick gravely swells and deforms. That is to say, the brick is nearly to break. The analysis results revealed that the major matters contained in the tumor-like eroding block are zinc and its oxides. Thus, the authors thought that: the enrichment, growth and expansion of zinc are the primary factors to result in the swell and breakage of the tuyere bricks and finally the upward-warp of the tuyeres.

\subsection{Process of zinc crystallization and its growth in the brick}

Fig.3 gave the SEM photos of zinc crystallization and its growth in tuyere brick samples. Fig.3a corresponds to the tuyere brick having light erosion, in which the crystal of zinc is a black speckle-like one. Next, Fig.3b corresponds to the tuyere brick having serious erosion and loose inner structure, in which the crystal of zinc is a gray-black grid-like one. Finally, Fig.3c corresponds to the tuyere brick having the worst erosion, which is nearly to disaggregate and break, and in which the crystal of zinc is a black ball-like one. According to these results, zinc crystallization and its growth in the brick would follow the process: the speckle- and slice-like crystallization firstly forms in the dense bricks, and then gradually connects, merges and grows to grid-like crystallization, making the strength of the brick drop down and the inner structure loose. As the final step, the crystal keeps growing to be ball-like, leading the tuyere bricks to gravely swell and even break. Fig.3d gives the element analysis of the ball-like crystal inner, which mainly consists of Zn. 


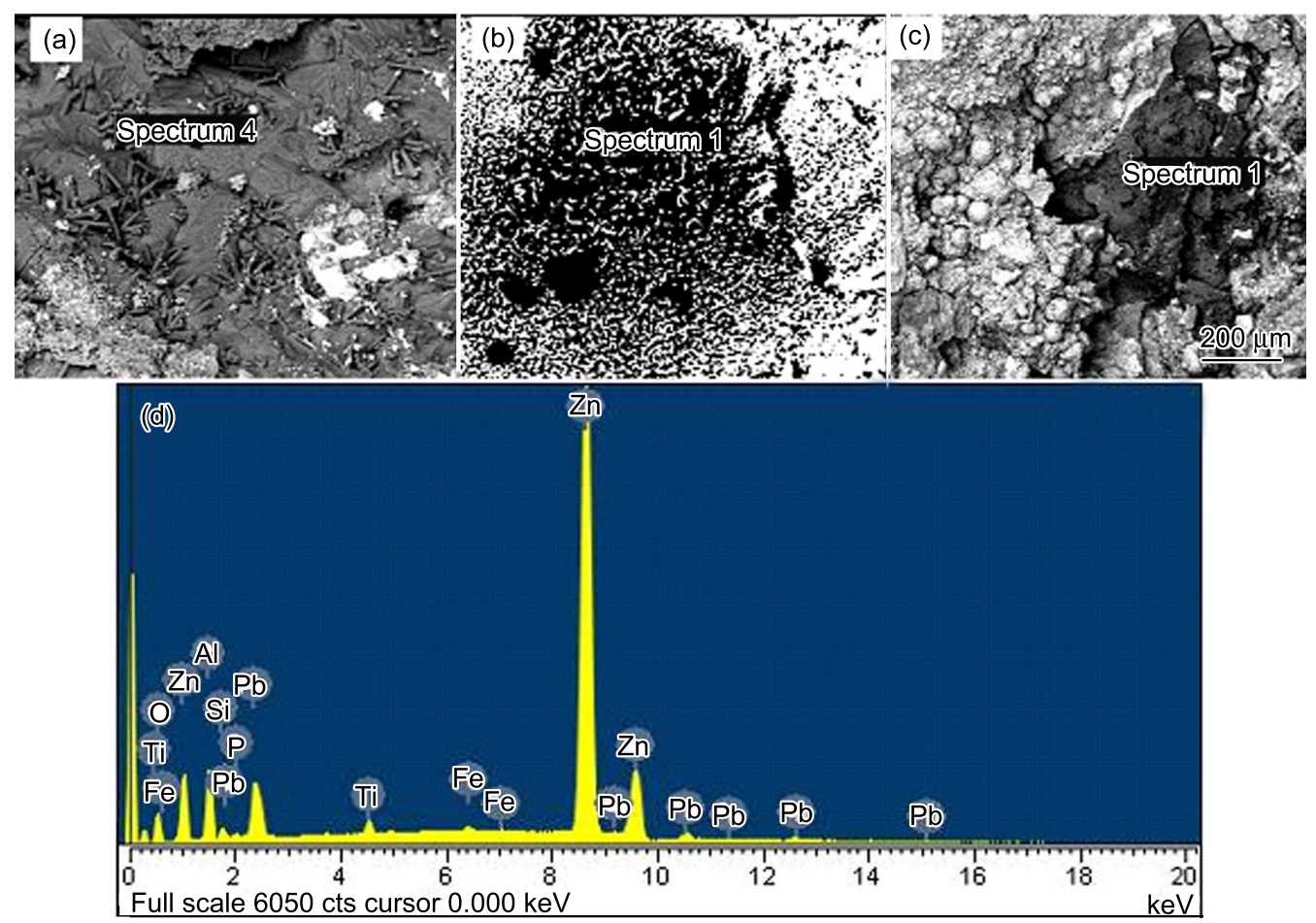

Fig.3 SEM photos (a-c) and EPMA (d) test of zinc crystallization and its growth in the tuyere brick samples gravely eroded.

\subsection{Superimposing effects of the deleterious elements}

For No.6 blast furnace in Kunming Steel, all the loads of the deleterious elements in the burdens are at a relatively high level, for example, alkali metal load is $4.71 \mathrm{~kg} / \mathrm{THM}$, zinc load $0.788 \mathrm{~kg} / \mathrm{THM}$ and lead load $0.337 \mathrm{~kg} / \mathrm{THM}$.

According to the above test results of EPMA, the erosion of the tuyere bricks are not caused by the effect of only one deleterious element, but the superimposing effects of deleterious elements including $\mathrm{K}, \mathrm{Na}, \mathrm{Zn}$ and $\mathrm{Pb}$ and the latter far exceeds the former, which represents the major characteristics of the refractory erosion in the blast furnace of Kunming Steel.

\section{Conclusions}

In this study, the authors focused on analyzing the generation reason of the tuyeres upward-warp in the blast furnace of Kunming Steel and elucidating the mechanism of the deleterious elements, represented by zinc, damaging to the tuyere refractory. Based on the observation and analysis, the following conclusions could be drawn.

(1) The primary factor to result in the upward-warp of the tuyeres is the damage of zinc, to the tuyere bricks with high zinc load in the charged burden of the blast furnace.

(2) Under the conditions of Kunming Steel, the sequence of the deleterious elements entering the tuyere brown corundum bricks is $\mathrm{K} \rightarrow \mathrm{Na} \rightarrow \mathrm{Zn} \rightarrow \mathrm{Pb}$.

(3) With the invasion, enrichment and growth of the above deleterious elements, especially zinc, the inner structure of tuyere bricks turns from dense to loose, and spot- 
like $\rightarrow$ stripe-like $\rightarrow$ ditch-like $\rightarrow$ vein-like $\rightarrow$ tumor-like eroding passage are generated, which finally result in the breakage of the tuyere bricks.

(4) The crystallization and its growth of zinc in the brick follow such a process as: the speckle- and slice-like crystallization firstly forms in the dense bricks, and then gradually connects, merges and grows to grid-like crystallization, making the strength of the brick drop down and the inner structure loose. Afterward, the crystal keeps growing to become ball-like, leading the tuyere brick to gravely swell and even break.

Acknowledgements - This paper is supported by Program for New Century Excellent Talents in University (NCET-2008-0099).

\section{REFERENCES}

[1] X. Yang, M. Chu and T, Wang, Ironmaking 24 (2005) 1.

[2] K. Narita, Steel in Translation 17 (1982) 8.

[3] K. Ru, Proc. on Deleterious Elements in Blast Furnace (Shuicheng Steel Company, Shuicheng, China, 1983).

[4] D. Zhu, Proc. on Deleterious Elements in Blast Furnace (Shuicheng Steel Company, Shuicheng, China, 1983).

[5] X. Wang, Iron and Steel Research 19 (1992) 36.

[6] Z. Li, Technology of Bao Steel 19 (2002) 18.

[7] Y. Shchukin, V. Sedinkin and M. Polushkin, Steel in Translation 29 (1999) 6.

[8] V.I. Gladyshev, V.V. Filippov and V.S. Rudin, Steel in Translation 31 (2001) 11.

[9] A. Hafez, M. Elmanharawy and M. Abdel, Intl J Environment Pollution 12 (2002) 359. 